\title{
Effect of palmitoleic acid on the differentiation of bovine skeletal muscle satellite cells
}

Junfang Zhang ${ }^{1,2 \#}$, Qiang Li, ${ }^{1,2 \#}$, Kim Margarette Corpuz Nogoy ${ }^{3}$, Jianfu Sun ${ }^{1,2}$, Bin Sun ${ }^{1,2}$,Ying Wang ${ }^{1,2}$, Lin Tang ${ }^{1,2}$, Jia Yu ${ }^{3}$, Xin Jin ${ }^{1,2}$, Xiangzi $\mathrm{Li}^{1,2 *}$ and Seong-Ho $\mathrm{Choi}^{3 *}$

${ }^{1}$ Engineering Research Center of North-East Cold Region Beef Cattle Science \& Technology Innovation, Ministry of Education, Yanbian University, Yanji 133002, China ${ }^{2}$ Department of Animal Science, Yanbian University, Yanji 133002, China

${ }^{3}$ Department of Animal Science, Chungbuk National University, Cheongju 28644, Korea

\section{Abstract}

We hypothesized that the unsaturated fatty acid palmitoleic acid (POA) could promote the expression of adipogenic/lipogenic genes in bovine skeletal muscle satellite cells (BSCs). The BSCs were cultured in a growth medium containing $10 \%$ fetal bovine serum. When the cells reached $80 \%-90 \%$ confluence, we used the differentiation medium with $5 \%$ horse serum for differentiation for $96 \mathrm{~h}$. The differentiation medium contained $50 \mu \mathrm{M}, 100 \mu \mathrm{M}$ and $200 \mu \mathrm{M}$ POA. Control BSC were cultured only in differentiation media. Compared with the control BSC, the POA BSC significantly up-regulated the expression of paired box 3 ( $P a \times 3)$ and paired box 7 (Pax7) and down-regulated myogenin gene expression $(p<0.01)$, which indicates a depression in muscle fiber development. However, all POA treatments up-regulated the expression of the adipocyte transcription factors peroxisome proliferator-activated receptor y (PPARY), CCAAT/enhancer-binding protein alpha and beta (C/EBP $\alpha$ and C/EBP $\beta)$, and other genes $(p<0.01)$ and increased the expression of PAT-family proteins and the concentration of adiponectin in the media. These results indicate that POA can convert part of BSCs into adipocytes.

Keywords: Adipocytes, Palmitoleic acid, Satellite cells, Bovine, Muscle, Marbling

\section{INTRODUCTION}

Marbling is an important feature of beef quality [1]. It is particularly important in determining the price of beef in South Korea, Japan, and the United States because of its impact on tenderness, juiciness, and flavor [2]. Currently, with the rapid growth of high-grade beef demand in China's domestic market, increasing intramuscular fat deposition has become a research hotspot in Chinas beef industry [3]. Deposition of intramuscular fat is influenced by both genetic factors (such as breed, gender, and genotype) and non-genetic factors (such as castration, nutrition, stressors, and animal weight and age) [4,5]. Intramuscular adipocytes are formed by the lipid filling of fibroblastic cells within the perimysium, and marbling consists of fat cells distributed between muscle fibers [6-8]. In addition, the 
Kim Margarette Corpuz Nogoy https://orcid.org/0000-0002-0958-7632 Jianfu Sun

https://orcid.org/0000-0001-7242-8784

Bin Sun

https://orcid.org/0000-0003-1768-6734

Ying Wang

https://orcid.org/0000-0002-5662-909X

Lin Tang

https://orcid.org/0000-0003-0276-8550

Jia Yu

https://orcid.org/0000-0003-3035-0397

Xin Jin

https://orcid.org/0000-0002-0630-3905

Xiangzi Li

https://orcid.org/0000-0003-3061-3847

Seong-Ho Choi

https://orcid.org/0000-0001-8869-0218

Competing interests

No potential conflict of interest relevant to this article was reported.

Funding sources

This study was funded by the National Natural Science Foundation in China (Grant number 31660667) and the National

Research Foundation in Korea (grant number NRF-2018R1D1A3B07048219). This study also was supported by the Research Fund of Engineering Research Center of NorthEast Cold Region Beef Cattle Science \& Technology Innovation, Ministry of Education and the "111" Project (D20034), China.

Acknowledgements

Not applicable.

Availability of data and material Upon reasonable request, the datasets of this study can be available from the corresponding author.

Authors' contributions

Conceptualization: Li X

Data curation: Sun B, Wang Y.

Formal analysis: Li Q.

Methodology: Zhang J, Li Q, Sun J.

Software: Zhang J, Li Q, Sun J.

Validation: Nogoy KMC, Yu J, Jin X.

Investigation: Sun B, Wang Y, Tang L.

Writing - original draft: Zhang J, Li Q.

Writing - review \& editing: Choi SH, Li X.

Ethics approval and consent to participate All experimental procedures involving animals were conducted using the approval code YBU-20160303 provided by the Yanbian University Institutional Animal Care and Use Committee. composition of fatty acids in meat, especially monounsaturated fatty acids (oleic and palmitoleic acids [POA]), is positively correlated with beef flavor [9].

Satellite muscle cells located between the myometrium and the basement membrane are pluripotent stem cell populations composed of Pax7-expressing progenitor cells [10]. They have mesenchymal plasticity, being able to commit either to myogenesis or to a mesenchymal alternative differentiation program [11]. Earlier studies have shown that cells from myogenic cultures that have showed myogenic response could be transferred from this pathway when treated with bonemorphogenetic proteins or adipogenic-inducing agents $[12,13]$. Our previous studies have shown that oleic acid, as the most abundant monounsaturated fatty acid in beef marbling, has the ability to differentiate microsatellite cells into adipocyte-like lipid droplets [14].

However, it is not clear whether POA, the second most abundant monounsaturated fatty acid in beef marbling, has the same characteristics as oleic acid. Therefore, we hypothesized that treatment of bovine skeletal muscle satellite cells with POA can induce the differentiation of muscle satellite cells into adipocytes, thereby promoting the formation of intramuscular fat and improving the quality of beef.

\section{MATERIALS AND METHODS}

\section{Animal use}

All experimental procedures involving animals were conducted using the approval code YBU20160303 provided by the Institutional Animal Care and Use Committee of Yanbian University.

\section{Isolation of bovine satellite cells}

Bovine satellite cells (BSCs) were isolated from the semimembranosus muscle of six 18-month old Yanbian Yellow cattle raised at Yanbian University. The BSCs were excides from the muscle tissue samples as previously described [14]. In brief, the muscle samples were minced and digested using $1 \mathrm{mg}$ Pronase (10165921001, Roche, Basel, Swiss) in $1 \mathrm{~mL}$ of Earl's Balanced Salt Wash (EBSS, Sigma-Aldrich, St. Louis, MO, USA). After digestion, the mixture were subjected to differential centrifugation to collect the mononucleated cells, which were suspended in Dulbecco's Modified Eagle's medium ([DMEM] Gibco, Thermo Fisher Scientific, Waltham, MA, USA) that contained 10\% fetal bovine serum ([FBS] Gibco, Thermo Fisher Scientific), 10\% (v/v) dimethyl sulfoxide ([DMSO] Sigma-Aldrich) and 1× antibiotic-antimycotic (Gibco, Thermo Fisher Scientific). The cells were frozen and stored in liquid nitrogen for subsequent studies.

\section{Bovine satellite cell culture, cell viability and size}

The BSCs were cultured in growth media composed of DMEM, 10\% FBS, 1\% penicillin/ streptomycin at optimal cell growth conditions in incubator $\left(38.5^{\circ} \mathrm{C}, 95 \% \mathrm{O}_{2}\right.$, and $5 \% \mathrm{CO}_{2}$ ). The cell cultures were fed with growth medium every $48 \mathrm{~h}$. Cell cultures that reached 80\%-90\% confluence were induced to differentiate by switching from growth medium to a differentiation medium comprised of DMEM, 5\% horse serum (HS), and 1\% penicillin/streptomycin. The differentiating or proliferating BSCs were exposed to different concentrations of POA $(50 \mu \mathrm{M}$; $100 \mu \mathrm{M}$; and $200 \mu \mathrm{M}$, Sigma-Aldrich) or to none-POA (control cells) in media for $96 \mathrm{~h}$. POA was dissolved in ethanol $(100 \mathrm{mmol} / \mathrm{L})$ prior to its addition to the cell cultures [15]. To measure the viability and size of the cells, the BSCs were harvested and stained with trypan blue staining for measurement Luna automatic cell counter (Logo Biosystems, Anyang, Korea). The experiment was conducted in triplicates or in three independent incubations. 


\section{Cell proliferation using MTT assay}

The cell proliferation was determined by MTT assay using the Cell Proliferation Reagent Kit (MTT ST316, Beyotime, Shanghai, China). The BSCs were seeded in 96-well plates at a seeding density of $2 \times 10^{3}$ cells and maintained for 24 and $48 \mathrm{~h}$ in 10\%-FBS growth media. The cells were then incubated with $5 \mathrm{mg} / \mathrm{mL}$ MTT in phosphate buffered saline (PBS) for $4 \mathrm{~h}$, after which the formazan crystals were dissolved by adding $150 \mu \mathrm{L}$ DMSO to each well where the plates were shaken for 10 minutes to fully dissolve the formazan crystals. The absorbance was measured using a microplate reader at $490 \mathrm{~nm}$ wavelength (reference wavelengths $450 \mathrm{~nm}, 570 \mathrm{~nm}$ ). The results were obtained and used to draw the cell growth curve with as abscissa and absorbance as the ordinate.

\section{Immunostaining}

To verify whether the cells isolated were BSC, the primary cells were stained for immunofluorescence. Cultured satellite cells were fixed with ice-cold $4 \%$ paraformaldehyde for $20 \mathrm{~min}$, rinsed twice with PBS, and permeated with $0.2 \%$ Triton $\mathrm{x}-100$ (in PBS) at room temperature for 30 min. The permeabilized cells were blocked with PBS containing 5\% bovine serum albumin (BSA) and shaken at room temperature for $1 \mathrm{~h}$, and incubated with primary antibodies: polyclonal anti-myogenic differentiation 1 (MYOD1; BS-2442R, Bioss, Woburn, MA, USA), anti-Pax7 (AB-528428, Abcam, Cambridge, UK), and anti-desmin Po (BS-20702R, Bioss) in 5\% BSA at 1:100 dilutions for $2 \mathrm{~h}$ at room temperature. After washing with PBS, the cells were incubated with HRP-labeled Goat Anti-Mouse IgG (H + L) (A0216, Beyotime, Shanghai, China) or Goat Anti-rabbit IgG-HRP antibody (BS-3550R, Bioss) for $2 \mathrm{~h}$ at room temperature in dark room and mounted in $0.1 \mu \mathrm{g} / \mathrm{mL}$ DAPI solution for $30 \mathrm{~min}$. The staining of the cells was observed using a fluorescence microscope (WF10X, Olympus, Tokyo, Japan) afterwards.

\section{Oil-Red-O staining and lipid droplet area quantitation}

The Oil-Red-O was used to confirm and quantify the accumulation of lipid droplets in differentiated BSCs treated without or with POA. The specific staining process was performed according to the instructions provided by Oil Red O Staining Kit (G1262, Solarbio, Beijing, China). Briefly, the cells were fixed with $10 \%$ neutral buffer formalin, after which the cultures were stained with $0.5 \%$ Oil-Red-O solution in darkness. The adipocytes were identified by the presence of lipid droplets. Images of the lipid droplets were taken using collected using an inverted bio microscope (IX-73, Olympus). Images of intracellular lipid droplets stained using the Oil Red O kit were analyzed by computer image using the ImageJ software (https://imagej.nih.gov/ij/) and the method of analysis described by Deutsch et al. [16] was followed. Briefly, the 8-bit red-greenblue image was threshold converted into a binary image consisting only the pixels that represent the lipid droplets, after which the images were watershed object separated to identify the borders of adjacing lipid droplets, and the scale of the images was set. The amount and individual size of the lipid droplets in the image presented by ImageJ as surface area in square micrometers $\left(\mu \mathrm{m}^{2}\right)$ were measured thereafter.

\section{Quantitative triacylglycerol assay}

The triacylglycerol (TAG) in culture cells was measured using the TAG assay kit (Applygen Technologies, Beijing, China). The cells were washed with PBS three times to remove residual medium, and were then lysed with RIPA lysis buffer (10 min). Accumulated triglyceride was digested to release the TAG into the lysate and aliquots were removed and the amount of glycerol liberated from TAG was determined by spectrophotometric detection at $570 \mathrm{~nm}$ and is linear over a glycerol concentration of $0-500 \mu \mathrm{M}$. 


\section{Adiponectin in bovine satellite cell culture media}

The adiponectin in BSC culture media was analyzed using a bovine adiponectin ELISA kit (Mlbio, Shanghai, China), and the analysis was conducted by following the manufacturer's protocol. The adiponectin concentration was measured with a microplate reader (iMark, BIO-RAD, Hercules, CA, USA) at $450 \mathrm{~nm}$, and a reference curve was generated using reference standards of known concentrations of adiponectin in the same assay. The reference curve was used to calculate the amount of adiponectin in the samples. The mean interassay precision was $<8.4 \%$, and the intraassay precision was $<5.7 \%$ for the adiponectin assay.

\section{Extraction of RNA and real-time polymerase chain reaction}

Total RNA was extracted from cells incubated for $96 \mathrm{~h}$ using Trizol reagent (Thermo Fisher Scientific) according to the manufacturer's instruction. $1 \mu \mathrm{g}$ of RNA from each treated cell was reversed transcribed to cDNA using a FastKing one-step method (Tiangen Biotech, Beijing, China) according to the manufacturer's protocol. The gene expression levels were determined using the appropriate forward and reverse primers and performed using the SuperReal PreMix Plus (SYBRGreen, Tiangen Biotech) with the Agilent Fast Real-Time PCR System using). The sequences of the primers are given in Table 1, and the target genes were as follows: paired box 3 (Pax3) and paired box 7 (Pax7), myogenic differentiation antigen (MYOD), myogenin (MYOG), myofactor-5, and myofactor-4 (MYF5, MRF4) are the myogenic-specific marker genes selected to determine the degree of myogenesis in cultured BSCs; peroxisome proliferator-activated receptor gamma $(P P A R \gamma)$, CCAAT/enhancer-binding protein alpha $(\mathrm{C} / \mathrm{EBP} \alpha)$ and beta $(\mathrm{C} / \mathrm{EBP} \beta)$, G-protein coupled receptor 43 (GPR43), sterol-regulated binding protein 1 (SREBP1), and stearoyl coenzyme-A desaturation enzyme (SCD), carnitine palmitoyltransferase 1 (CPT1), AMPactivated protein kinase alpha-1 (AMPK $\alpha$ ), fatty acid synthase (FASN), lipoprotein lipase (LPL), glycerin-3-phosphate acyltransferase 3 (GPAT3), lipid droplet formation-related protein, perilipin (PLIN1), adipose differentiation-related protein (adipophilin; PLIN2), and tail-interacting protein of $47 \mathrm{kDa}$ (TIP47/PLIN3) were the adipogenic/lipogenic gene markers used to analyze the differentiation of BSCs into adipocytes at different concentrations of the POA. The thermal cycling parameters were as follows: pre-denaturation of samples at $95^{\circ} \mathrm{C}$ for $15 \mathrm{~min}$, then amplification for 40 cycles, which consisted of $10 \mathrm{~s}$ at $95^{\circ} \mathrm{C}, 30 \mathrm{~s}$ at $55^{\circ} \mathrm{C}$ and $30 \mathrm{~s}$ at $72^{\circ} \mathrm{C}$, with a melting curve from $65^{\circ} \mathrm{C}$ to $95^{\circ} \mathrm{C}$. The $2^{-\Delta \Delta \mathrm{ct}}$ method was used to determine the relative fold-changes and all data were normalized with the housekeeping gene glyceraldehyde-3-phosphate dehydrogenase (GAPDH).

\section{Western blot analysis}

Equal amounts of protein samples ( $30 \mu \mathrm{g} / \mathrm{sample})$ were separated electrophoretically by $10 \%$ sodium dodecyl sulphate (SDS)-polyacrylamide gel electrophoresis (PAGE), blotted onto a PVDF membrane (Millipore, Billerica, MA, USA), and probed with primary and secondary antibodies. Primary antibodies used were Desmin (bs-20702R), PPAR $\gamma$ (bs-4509R), C/EBP $\alpha$ (bs-1630R), MYOD (bs-2442R), and MYOG (bs-3550R), and the secondary antibodies were horseradish peroxidase-labelled goat anti-mouse or anti-rabbit IgG (bs-0295G) obtained from Bioss, while anti-Pax7 (AB-528428) and GAPDH (ab9484) were procured from Abcam.

\section{Statistical analysis}

The data in this study were all presented as mean \pm SEM. Significant differences among the treatments were analyzed using one-way analysis of variance and Post Hoc Tukey's multiple comparison test GraphPad Prism 6.07 (GraphPad Software, La Jolla, CA, USA) at significance level of $p<0.05$. 
Table 1. Forward and reverse primers for real-time PCR for specific gene mRNA

\begin{tabular}{|c|c|c|c|c|}
\hline Gene & Forward Primer sequence $\left(5^{\prime}-3^{\prime}\right)$ & Reverse Primer sequence (5'-3') & Product size (bp) & Gen Bank \\
\hline GAPDH & ACTCTGGCAAAGTGGATGTTGTC & GCATCACCCCACTTGATGTTG & 143 & NM_001034034 \\
\hline Pax3 & GGCTGCGTCTCTAAGATCCT & ATTTCCCAGCTGAACATGCC & 158 & NM_001206818 \\
\hline Pax7 & TGCCCTCAGTGAGTTCGATT & CGGGTTCTGACTCCACATCT & 180 & XM_015460690 \\
\hline MYOD & CCGACGGCATGATGGACTA & CTCGCTGTAGTAAGTGCGGT & 80 & NM_001040478 \\
\hline MYOG & CAGTGAATGCAGCTCCCATAG & GCAGATGATCCCCTGGGTTG & 86 & NM_001111325 \\
\hline MYF5 & CCСАССTCAAGTTGCTCTGA & CCGTGGCATATACATTTGGTACA & 115 & NM_174116 \\
\hline MRF4 & TGGACCCCTTCAGCTACAGA & ATGCTTGTCCCTCCTTCCTTG & 139 & NM_181811 \\
\hline PPARY & ATCTGCTGCAAGCCTTGGA & TGGAGCAGCTTGGCAAAGA & 138 & NM_181024 \\
\hline $\mathrm{C} / \mathrm{EBPa}$ & CCAGAAGAAGGTGGAGCAACTG & TCGGGCAGCGTCTTGAAC & 69 & GU947654 \\
\hline $\mathrm{C} / \mathrm{EBP} \beta$ & CAACCTGGAGACGCAGCACAAG & CGGAGGAGGCGAGCAGAGG & 143 & NM_176788 \\
\hline SREBP1 & GCAGCCCATTCATCAGCCAGACC & CGACACCACCAGCATCAACCACG & 146 & NM_001113302 \\
\hline GPR43 & GGCTTTCCCCGTGCAGTA & ATCAGAGCAGCGATCACTCCAT & 63 & NM_001163784 \\
\hline SCD & TGCCCACCACAAGTTTTCAG & GCCAACCCACGTGAGAGAAG & 80 & NM_173959 \\
\hline CPT-1 $\beta$ & ACACATCTACCTGTCCGTGATCA & СCCCTGAGGATGCCATTCT & 72 & NM_001034349 \\
\hline ACSL3 & ATGGGACTTGGGAGGAGCTGTG & GTCCACGGTTCAGGGCTCAAAC & 139 & NM_001205468 \\
\hline AMPKa & CACCAAGGTGTAAGGAAAGCA & ACGGGTTTACAACCTTCCATTC & 127 & NM_001109802 \\
\hline LPL & ACGATTATTGCTCAGCATGG & ACTTTGTACAGGCACAACCG & 130 & NM_001075120 \\
\hline FASN & СGCTTGCTGCTGGAGGTCAC & GGTCTCAGGGTCTCGGCTCAG & 141 & NM_001012669 \\
\hline GPAT3 & СCTGACTTGCTGCCGCATCTG & CGATTGGGGACGTATGGTTGG & 116 & NM_001192514 \\
\hline PLIN1 & ACCATCTCCACCCGCCTTCG & GCAGCATACTCGGCAGTGTCTC & 140 & NM_001083699 \\
\hline PLIN2 & GCTCCATTCCGCCTTCAACCTG & GCCGATGCTTCTCTTCCACTCC & 124 & NM_173980 \\
\hline PLIN3 & GCAGAGCGGCGTAGACTTGAC & CGTCATGGGCAGGTGGTTGTC & 148 & NM_001077046 \\
\hline CD36 & TTGGTGATGAGAAGGCGGAA & ACCAACACTGAGCAAGACGA & 92 & XM_024990438 \\
\hline Leptin & AAGGAAAATGCGCTGTGGAC & CACAGCCTCCACGTAAGACA & 73 & NM_173928 \\
\hline $\mathrm{ADI}$ & CCATCCTGATGTCGTCTCAC & CTCCTCGGCTTTGGTTGGG & 158 & NM_001034055 \\
\hline
\end{tabular}

PCR, polymerase chain reaction; GAPDH, glyceraldehyde 3-phosphate dehydrogenase; Pax3, paired box 3; Pax7, paired box 7; MYOD, myogenic differentiation antigen; MYOG, myogenin; MYF5, myofactor-5; MRF4, myofactor-4; PPARy, peroxisome proliferator-activated receptor gamma; C/EBPa, CCAAT/enhancer-binding protein alpha; C/EBP 3 , CCAAT/ enhancer-binding protein beta; SREBP1, sterol-regulated binding protein 1; GPR43, G-protein coupled receptor 43; SCD, stearoyl coenzyme-A desaturation enzyme; CPT1 $\beta$, carnitine palmitoyltransferase 1 beta; ACSL3, acyl-CoA synthetase long-chain 3; AMPKa, AMP-activated protein kinase alpha-1; LPL, lipoprotein lipase; FASN, fatty acid synthase; GPAT3, glycerin-3-phosphate acyltransferase 3; PLIN1, lipid droplet formation-related protein, perilipin; PLIN2, adipose differentiation-related protein (adipophilin); PLIN3, tail-interacting protein of $47 \mathrm{kDa}$ (TIP47); ADI, adiponectin.

\section{RESULTS}

Average cell size and cell viability

The average cell size in CON $+100 \mu \mathrm{M}$ POA ([POAM] $20.60 \pm 0.50 \mu \mathrm{m})$ and $\mathrm{CON}+200 \mu \mathrm{M}$ $\mathrm{POA}([\mathrm{POAH}] 23.36 \pm 0.39 \mu \mathrm{m})$ treatments was higher than that of $\mathrm{CON}(15.93 \pm 0.27 \mu \mathrm{m})(p$ $<0.001)$, whereas there was no significant difference between CON $(15.93 \pm 0.27 \mu \mathrm{m})$ and $\mathrm{CON}$ $+50 \mu \mathrm{M}$ POA $([\mathrm{POAL}] 17.20 \pm 0.20 \mu \mathrm{m})($ Fig. 1A). However, there was no difference in cell viability among the treatments $(p=0.9053$; Fig. 1B).

Yanbian Yellow Cattle bovine satellite cell are myogenic

Fig. 2A shows the formation of myotubes and the multinucleate nature of cells at 6 days postconfluence. We examined the expression of the myogenic markers MYOD and desmin. Pax7, in particular, was considered to be a marker of muscle satellite cells. Pax7, MYOD, and desmin were detected in the nuclei of both mononucleate and fused cells (Fig. 2B). 
A

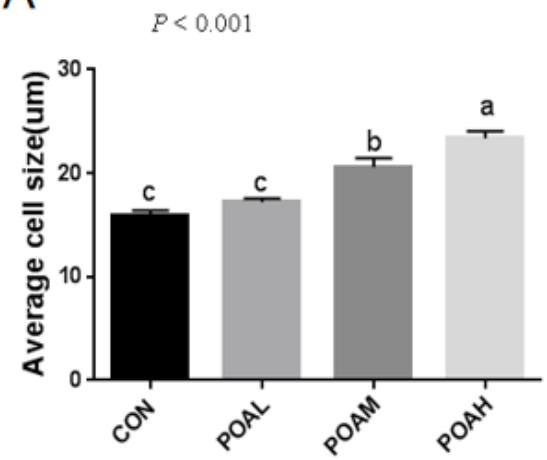

$\mathrm{B}$

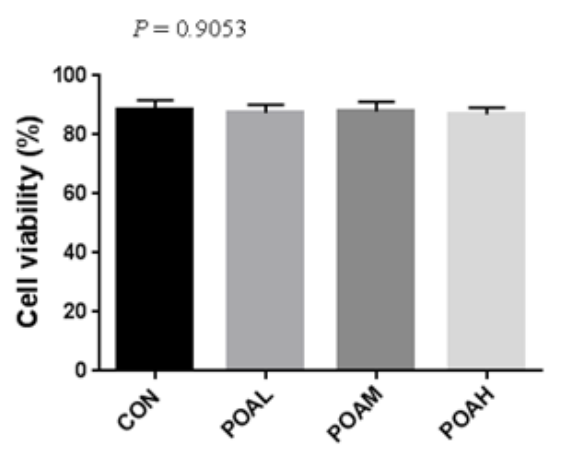

Fig. 1. Effects of different concentrations of palmitoleic acid (POA) on average cell size (A) and cell viability (B) in bovine satellite cells after 96 -h culture. Control group (CON), DMEM $+5 \%$ horse serum; POAL, CON + $50 \mu \mathrm{M}$ POA; POAM, CON + $100 \mu \mathrm{M}$ POA; POAH, CON + $200 \mu \mathrm{M}$ POA. Values with a different letter ( $\mathrm{a}$ or $\mathrm{b}$ or $\mathrm{c}$ ) above column differ significantly $(p<0.05)$. The same superscript or no superscript on the column means that the difference is not significant $(p>0.05)$. DMEM, Dulbecco's Modified Eagle's medium.

A
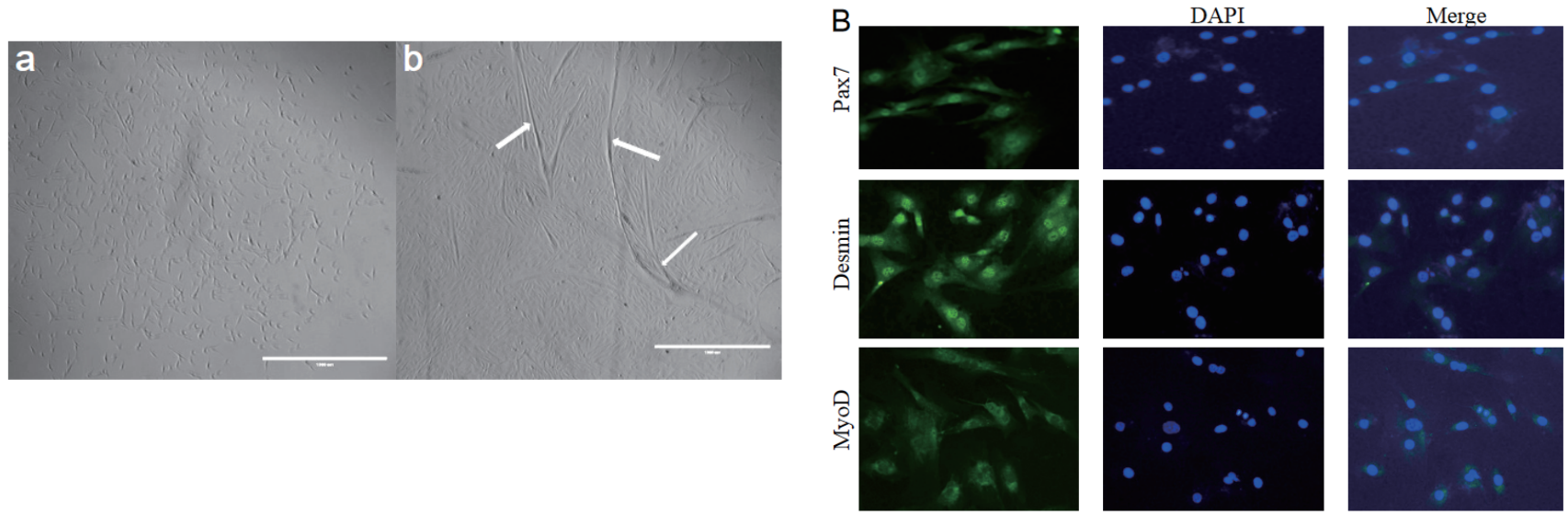

Fig. 2. Identification of Yanbian Yellow Cattle BSC. (A) (a) Cells began to adhere to the wall and grew in a long shuttle shape; (b) Cell fusion occurs and multinuclear myotubes begin to form. The arrows indicate the fused cells. (B) The expressions of Pax7, Desmin and MyoD were identified by immunofluorescence staining. After DAPI staining, the nuclei were blue, and the cytoplasm of Pax7, Desmin and MYOD were green. The magnification is $\times 40$ (scale bars = $200 \mu \mathrm{m}$ ). DAPI, 4',6-diamidino-2-phenylindole; Pax7, paired box 7; MyoD, myogenic differentiation antigen; BSC, bovine satellite cells.

Lipid accumulation in cells and adiponectin in culture medium after $96 \mathrm{~h}$ : bovine satellite cell differentiation

The adipogenic differentiation of BSC was induced by adding POA to the differentiation medium with 5\% HS. Oil red O staining was positive after $96 \mathrm{~h}$ of differentiation culture. Cells added to the POA group gradually developed into adipocyte-like cells, which did not occur in cells in CON. Moreover, with the increase of POA concentration, the area of lipid droplets increased significantly (Fig. 3A). The adiponectin concentration in the medium also increased with the POA concentration (Fig. 3D).

Intracellular triacylglycerol content and lipid droplet area after bovine satellite cell differentiation culture for $96 \mathrm{~h}$

Compared with CON, different concentrations of POA significantly increased intracellular TAG content and lipid droplet area (Fig. 3). And the higher the concentration of POA added, the higher 

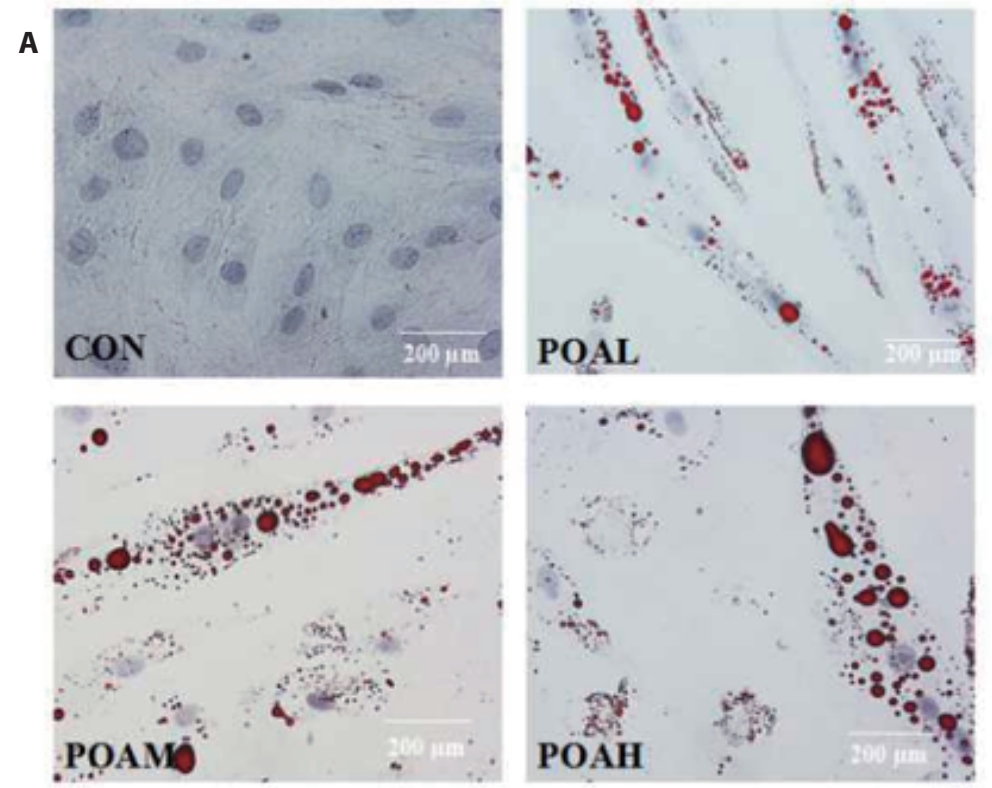

B

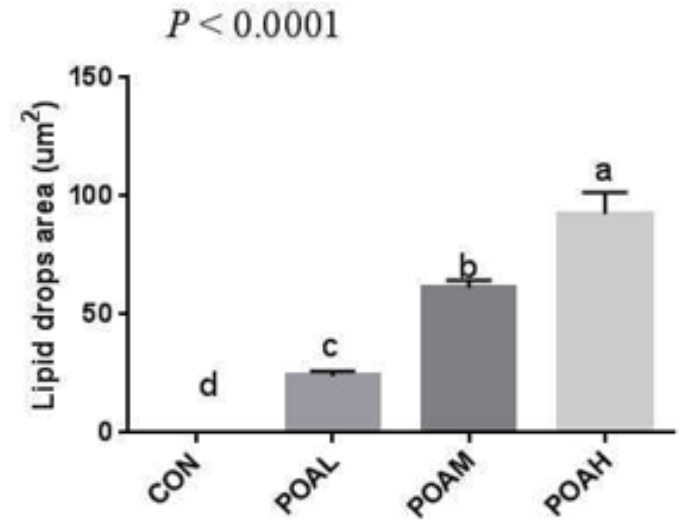

D $\quad P<0.0001$

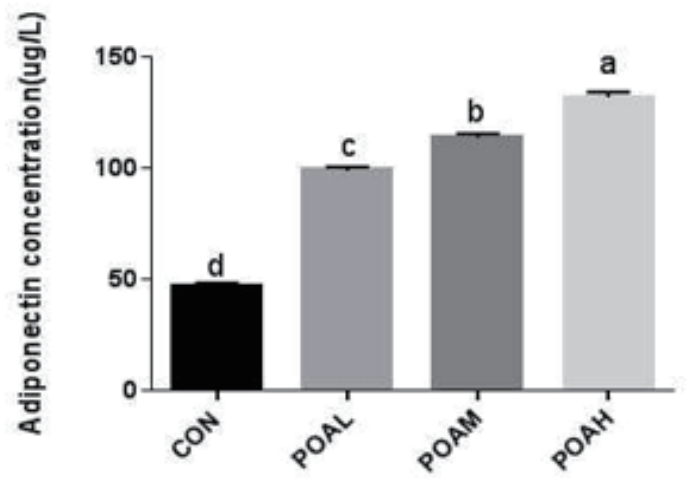

Fig. 3. Oil-red-o, lipid droplet area, intracellular triacylglycerol, and lipid droplet area analyses after differentiation of BSC for $96 \mathrm{~h}$. (A) Oil red staining after 96-h incubation of BSC treated with POA (scale bars $=200 \mu \mathrm{m}$ ), (B) effects of different concentrations of POA on lipid droplet area in BSC at 96-h culture tim, (C) Effects of different concentrations of POA on intracellular triacylglycerol in BSC at 96-h culture time, (D) adiponectin concentration $(\mu \mathrm{g} / \mathrm{L})$ in the medium after $96 \mathrm{~h}$ differentiation culture of BSC with POA. CON, DMEM + 5\% HS; POAL, CON + $50 \mu \mathrm{M}$ POA; POAM, CON + $100 \mu \mathrm{M}$ POA; POAH, CON + $200 \mu \mathrm{M}$ POA. BSC, bovine satellite cells; POA, palmitoleic acid; DMEM, Dulbecco's Modified Eagle's medium; HS, horse serum.

the intracellular TAG content (Fig. 3C), and the lipid droplet area also increased significantly (Fig. 3B).

\section{Gene expression and related protein expression \\ Myogenic genes and proteins}

Compared with CON, POA showed increased expression of $\operatorname{Pax3}(p<0.0001$; Fig. 4A) and Pax7 $(p<0.0001$; Fig. 4B) genes. Different concentrations of POA significantly inhibited the expression of myogenic genes MYOD, MYOG, MYF5, and MRF4 ( $p<0.0001$; Fig. 4C, D, E, and F).

Western blot analysis was used to determine the expression levels of PAX7, MYOD, and MYOG. Results showed that POA treatment increased the protein expression of myogenic transcription factor PAX7 and decreased the MYOD and MYOG in BSC (Fig. 4G). 
A

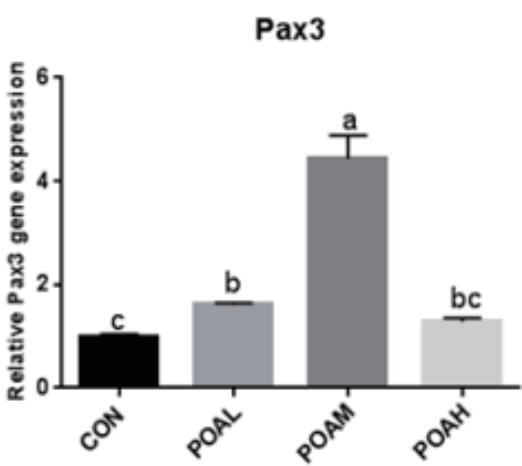

D

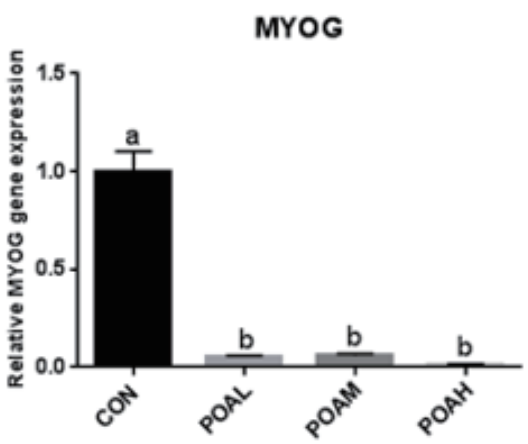

B

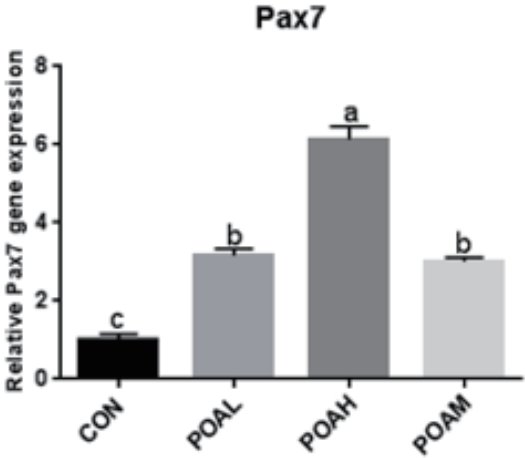

$\mathrm{E}$

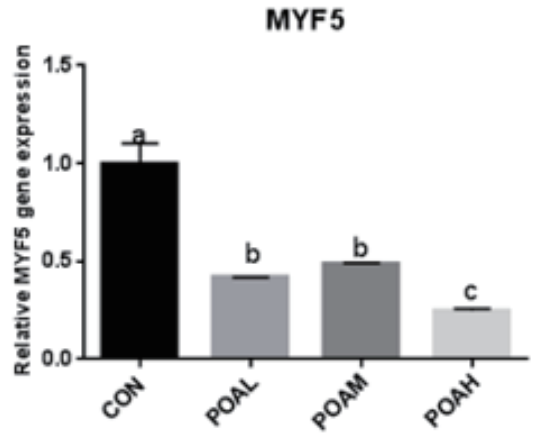

C

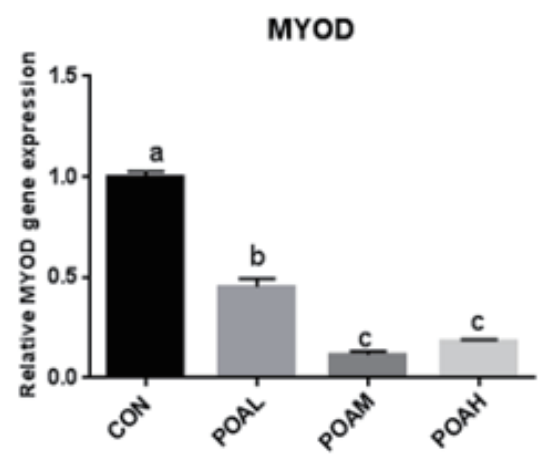

$\mathrm{F}$

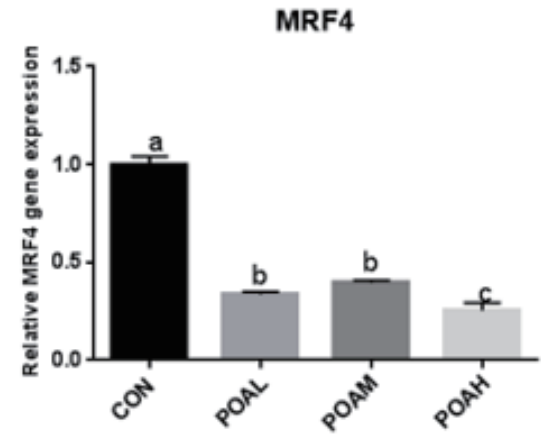

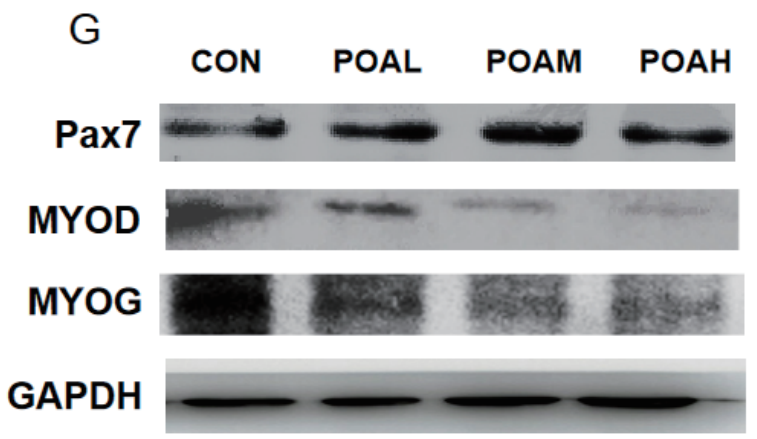

Fig. 4. Expression of myogenic genes and proteins. (A) Pax3, (B) Pax7, (C) MYOD, (D) MYOG, (E) MYF5, (F) MRF4, (G) expression of the indicated proteins was analyzed by western blot after treatment of the BSC with POA for $96 \mathrm{~h}$. CON, DMEM + 5\% HS; POAL, CON + $50 \mu \mathrm{M}$ POA; POAM, CON +

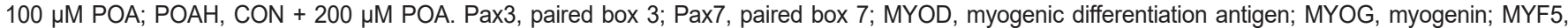
myofactor-5; MRF4, myofactor-4; GAPDH, glyceraldehyde 3-phosphate dehydrogenase; BSC, bovine satellite cells; POA, palmitoleic acid; DMEM, Dulbecco's Modified Eagle's medium; HS, horse serum.

\section{Adipogenic genes and proteins}

POAL, POAM, and POAH treatments showed increased PPAR $\gamma, \mathrm{C} / \mathrm{EBP} \alpha, \mathrm{SREBP} 1(p$ $<0.0001$; Fig. 5A, B, and C) expressions compared with CON, and POAH treatment showed the highest increase. POA treatment also promoted the expression of $\mathrm{C} / \mathrm{EBP} \beta, \mathrm{GPR} 43$, and CPT1 $\beta(p<0.0001$; Fig. 5D, E, and F) and other adipogenic genes. Western blot analysis was used to determine the expression levels of PPAR $\gamma, \mathrm{C} / \mathrm{EBP} \alpha$, and SREBP1 and POA treatment increased the protein expression of adipogenic transcription factors $\operatorname{PPAR} \gamma, \mathrm{C} / \mathrm{EBP} \alpha$, and 

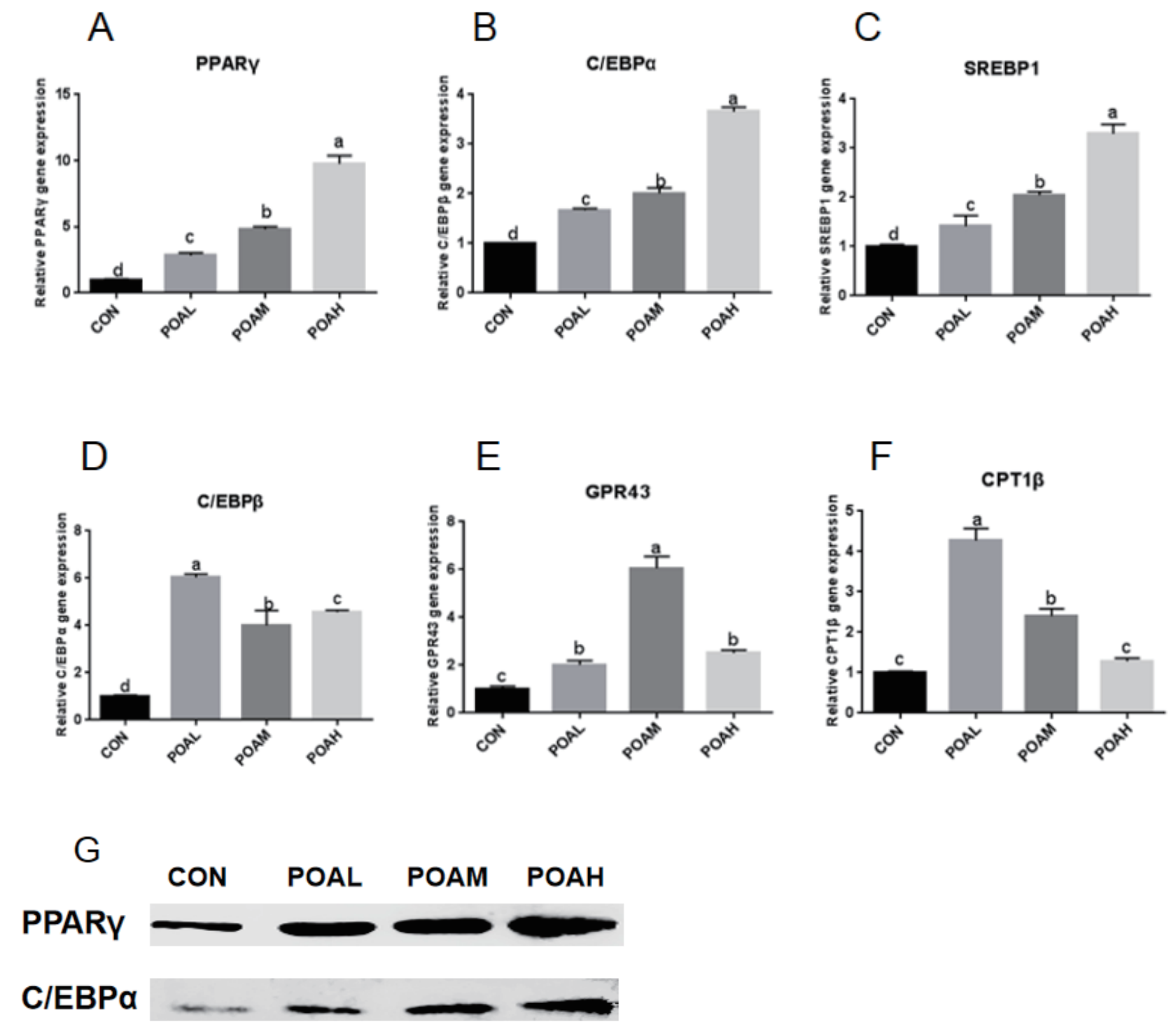

\section{SREBP1}

Fig. 5. Expression of adipogenic genes and proteins. (A) PPARy, (B) C/EBPa, (C) C/EBP $\beta$, (D) SREBP1, (E) GPR43, (F) CPT1 $\beta$ ), (G) expression of the indicated proteins was analyzed by western blot after treatment of the BSC with POA for $96 \mathrm{~h}$. CON, DMEM + 5\% HS; POAL, CON + $50 \mu \mathrm{MM}$ POA; POAM, $\mathrm{CON}+100 \mu \mathrm{M}$ POA; POAH, CON + $200 \mu \mathrm{M}$ POA. PARy, peroxisome proliferator-activated receptor gamma; C/EBPa, CCAAT/enhancer-binding protein alpha; SREBP1, sterol-regulated binding protein 1; C/EBP $\beta$, CCAAT/enhancer-binding protein beta; GPR43, G-protein coupled receptor 43; CPT1 $\beta$, carnitine palmitoyltransferase 1 beta; GAPDH, glyceraldehyde 3-phosphate dehydrogenase; BSC, bovine satellite cells; POA, palmitoleic acid; DMEM, Dulbecco's Modified Eagle's medium; HS, horse serum.

SREBP1 in BSC as shown in Fig. 5G.

\section{Lipid metabolism-associated genes}

Expression of SCD and AMPK $\alpha$ was lower in the POA treatment than in CON $(p<0.0001$; Fig. 6A and B); the expression of LPL was lower in the POAM and POAH treatments than in $\mathrm{CON}(p<0.0001$; Fig. 6C). However, the expression of genes related to fatty acid synthesis such as FASN, GPAT3, acyl-CoA synthetase long-chain 3 (ACSL3) was higher in THE POAM and 

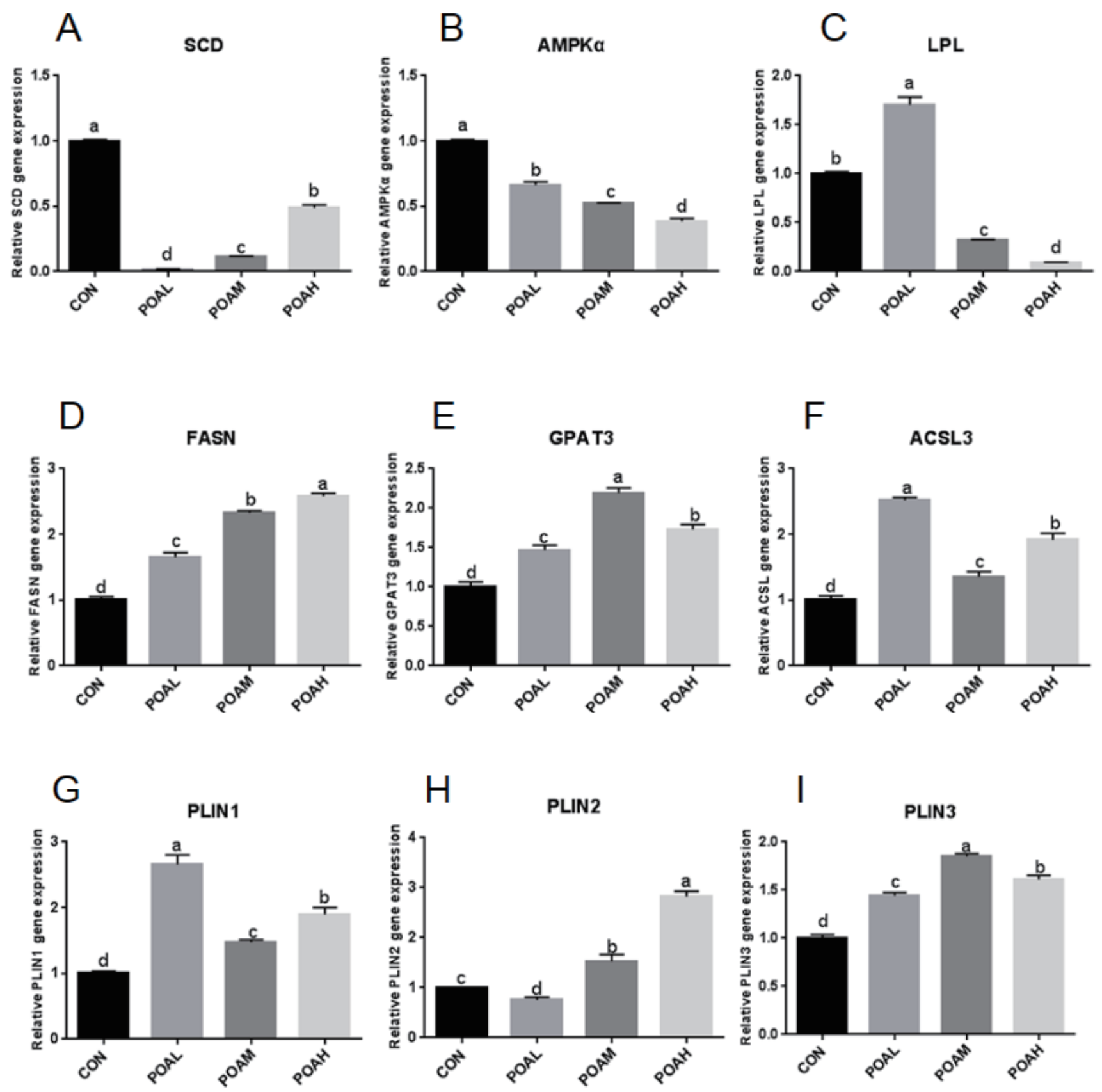

Fig. 6. Expression of lipid metabolism-associated genes. (A) SCD, (B) AMPKa, (C) LPL, (D) FASN, (E) GPAT3, (F) ACSL3, (G) PLIN1, (H) PLIN2, (I) PLIN3, (J) CD36, (K) Leptin, (L) ADI. CON, DMEM + 5\% HS; POAL, CON + $50 \mu M$ POA; POAM, CON + $100 \mu M$ POA; POAH, CON + $200 \mu M$ POA. SCD, stearoyl coenzyme-A desaturation enzyme; AMPKa, AMP-activated protein kinase alpha-1; LPL, lipoprotein lipase; FASN, fatty acid synthase; GPAT3, glycerin-3-phosphate acyltransferase 3; ACSL3, acyl-CoA synthetase long-chain 3; PLIN1, lipid droplet formation-related protein, perilipin; PLIN2, adipose differentiation-related protein (adipophilin); PLIN3, tail-interacting protein of 47 kDa (TIP47); ADI, adiponectin; DMEM, Dulbecco's Modified Eagle's medium; HS, horse serum; POA, palmitoleic acid.

POAH treatments than in CON $(p<0.0001$; Fig. $6 \mathrm{D}$, E, and F). Moreover, the expression of PAT family genes was positively correlated with the increasing concentrations of $\mathrm{POA}(p<0.0001$; Fig. $6 \mathrm{G}, \mathrm{H}$, and I); and POA also promoted the expression of CD36, Leptin, and Adiponectin, which are closely related to lipid synthesis (Fig. 6J, K, L, and M). 


\section{DISCUSSION}

The purpose of this study was to investigate the effect of POA on the differentiation of bovine BSCs. Previous studies have shown that BSCs can be isolated from adult Hanwoo muscle, and that BSCs can proliferate and be induced to differentiate into adipocytes [17]. Xu et al. [18] reported that all fatty acids did not affect the proliferation of bovine muscle-derived satellite cells (MDSC) through the study of proliferation rates and cell cycle progression, so we hypothesized that POA could promote the differentiation of BSCs. During the growth of skeletal muscle, the number of BSCs accounts for approximately $80 \%$ of the myonuclei. These numbers decrease to $4 \%-15 \%$ of the total nuclei in the muscle fiber as the animal approaches its mature size [19]. This decrease in BSCs is generally accompanied by cell differentiation or the formation of new muscle fibers [20]. In our experiment, after treating BSCs with different concentrations of the POA, there was no difference in the viability of BSCs, but a significant difference in cell size. We speculate that this may be caused by changes in cells during differentiation. Neutral lipids in skeletal muscle are mainly stored in lipid droplets in the form of TAGs [21]. We performed Oil Red O staining and determined intracellular TAG concentration after the 96-h incubation of BSCs treated with the POA. The results of Oil Red $O$ positive staining and the significant increase of TAG concentration confirmed our hypothesis that $\mathrm{POA}$ promoted the muscle satellite cells differentiation into adipocytes.

It has been shown that oleic acid, an 18-C unsaturated fatty acid, promotes adipose differentiation by up-regulating adipocytes transcription factor $\operatorname{PPAR} \gamma, \mathrm{C} / \mathrm{EBP} \alpha$, and $\mathrm{C} / \mathrm{EBP} \beta$ $[14,22,23]$. According to reports, BSCs can be transferred to adipocytes by using PPAR $\gamma$ agonists $[13,24,25]$. In this study, $\operatorname{PPAR} \gamma, \mathrm{C} / \mathrm{EBP} \alpha, \mathrm{C} / \mathrm{EBP} \beta$, and other adipocytes transcription factors expressions significantly increased in BSCs differentiated by the POA. In addition, the lipid metabolism factors CPT1 $\beta$ and GPR43 were up-regulated, but the expression of SCD and AMPK $\alpha$ were significantly inhibited, which was consistent with the research of [26,27]; that is, the inhibition of SCD catalytic activity reduced the activity of genes associated with de novo fatty acid synthesis, while increasing the expression of genes related to fatty acid oxidation, such as CPT1 $\beta$. AMPK is an important cellular energy sensor, which regulates metabolism and energy balance [28]. A large number of studies have shown that AMPK regulates the expression of polyester-related genes (e.g., PPAR $\gamma, \mathrm{C} / \mathrm{EBP} \alpha$, FAS, SREBP-1) in fat precursor cells differentiation through $\mathrm{Wnt} / \beta$-catenin, mTORC1, MAPK, and SIK signaling pathways [29,30]. In skeletal muscle, AMPK activation can increase sugar intake, enhance fat oxidation, and reduce TAG synthesis through phosphorylation of ACC2 [31]. Although the increased expression of CPT1 $\beta$ and other fatty acid oxidation-related genes induced by BSCs treated with POA may inhibit the aggregation of TAG and the formation of lipid droplets, the increase of TAGs in muscle is mainly caused by the imbalance between fat deposition and utilization ([32-35]).

In this study, although the POA treatment group up-regulated the expression of Pax3 and Pax7, it significantly down-regulated the expression of myogenic regulatory factors MYOD, MyoG, Myf5, and MRF4. Chung et al. [36] demonstrated that treating muscle cells in culture with 100 $\mu \mathrm{M}$ oleic acid and other growth factors down-regulated myogenin gene expression. The decreased expression of these myogenin genes suggests that the development of muscle fibers is inhibited.

Among TAGs-containing lipid droplets, a sub-population expands after their initial formation. TAG is locally generated by a series of enzymes such as GPAT3 and diacylglycerol O-acyltransferase 2 (DGAT2), which leads to linear volume expansion over time of these lipid droplets specifically [37]. The PAT-family proteins are a class of small protein molecules in lipid metabolism. Positioned at the lipid droplet surface, PAT proteins manage access of other proteins to the lipid esters within the lipid droplet core and can interact with cellular machinery important 
for lipid droplet biogenesis. PAT-family proteins are not directly involved in the synthesis and decomposition of lipids [38].

PLIN2 is present in the early stage of lipid droplet formation, promoting the formation of lipid droplets, and it is replaced by PLIN1 when the lipid droplets mature. Interestingly, the expressions of PLIN2 and PLIN1 are activated or inhibited by the co-activator PPAR $\gamma$ [39,40]. Adipose differentiation-related protein (ADRP) and perilipin are markers of cellular lipid accumulation [41,42]. Imamura et al. [43] showed that ADRP stimulated lipid accumulation and lipid droplet formation in murine fibroblasts by transporting endogenous free fatty acids from the cytosol to the surface of lipid droplets without induction of other adipocyte-specific genes or other lipogenic genes in murine fibroblast cells. Our study confirmed that after 96-h incubation of BSCs treated with POA, the gene expression of PAT-family proteins (PLIN1, PLIN2, and PLIN3) was significantly up-regulated, which was closely related to the formation of lipid droplets after differentiation, and further confirmed that BSCs can transdifferentiate into adipocytes.

In this study, POA significantly up-regulated the expression of leptin and adiponectin genes, especially in the POAH, and the concentration of adiponectin in the medium increased significantly. Leptin and adiponectin are two of the most important markers of adipocyte differentiation. Leptin is considered a pleiotropic hormone whose metabolic functions include appetite control, energy balance, and regulation of liposugar metabolism [44,45]. Adiponectin may be produced exclusively by adipocytes and plays a role in regulating insulin sensitivity [46-48]. As a fatty acid transporter, the main function of CD36 is to transport long-chain fatty acids, which can promote the absorption of free fatty acids in adipocytes, increase intracellular lipid accumulation, expand adipocyte volume, and also promote the transformation of preadipocytes into mature adipocytes, increasing the number of adipocytes $[49,50]$. This is consistent with the significant difference between the number of lipid droplets and the area of lipid droplets in cells with increasing POA concentration observed in our study.

In conclusion, treatment of BSC with POA can promote the transdifferentiation of BSCs into adipocytes where at least a portion of BSCs were converted into adipocytes as evidenced by the downregulations of myogenic related genes that caused the depression of muscle fiber development, and upregulation of adipogenic related genes that caused the transdifferentiation of muscle cells into adipocyte-like cells. This study demonstrated that POA was could be a positive regulator for differentiation of BSCs to ADPs. Our results suggest that POA could be useful in increasing the marbling content of beef to improve meat quality and this also shows that bovine satellite cells could be useful study models in the development of meat culture technology.

\section{REFERENCES}

1. Ladeira MM, Schoonmaker JP, Swanson KC, Duckett SK, Gionbelli MP, Rodrigues LM, et al. Review: nutrigenomics of marbling and fatty acid profile in ruminant meat. Animal. 2018;12:s282-94. https://doi.org/10.1017/s1751731118001933

2. Baik M, Kang HJ, Park SJ, Na SW, Piao M, Kim SY, et al. Triennial Growth and Development Symposium: molecular mechanisms related to bovine intramuscular fat deposition in the longissimus muscle.J Anim Sci. 2017;95:2284-303. https://doi.org/10.2527/jas.2016.1160

3. Chen J, Liu M, Li Z. The fractal dimension research of chinese and american beef marbling standards images. In: Proceedings of the International Conference on Computer \& Computing Technologies in Agriculture; 2012 Oct 19-21; Zhangiajie, China.

4. Hocquette JF, Gondret F, Baéza E, Médale F, Jurie C, Pethick DW. Intramuscular fat content in meat-producing animals: development, genetic and nutritional control, and identification of 
putative markers. Animal. 2010;4:303-19. https://doi.org/10.1017/s1751731109991091

5. Mach N, Bach A, Realini CE, Font IFM, Velarde A, Devant M. Burdizzo pre-pubertal castration effects on performance, behaviour, carcass characteristics, and meat quality of Holstein bulls fed high-concentrate diets. Meat Sci. 2009;81:329-34. https://doi.org/10.1016/j.meatsci.2008.08.007

6. Brooks M, Choi C, Lunt D, Miller R, Choi C, Smith S. Case study: carcass and meat characteristics and M. longissimus thoracis histology of beef from calf-fed and yearling-fed Angus steers. Prof Anim Sci. 2011;27:385-93. https://doi.org/10.15232/S1080-7446(15)30503-9

7. Moody WG, Cassens RG. A quantitative and morphological study of bovine longissimus fat cells.J Food Sci. 1968;33:47-52. https://doi.org/10.1111/j.1365-2621.1968.tb00882.x

8. Smith SB, Lunt DK. Marbling: management of cattle to maximize the deposition of intramuscular adipose tissue. In: Proceedings of the Plains Nutrition Council Spring Conference; 2007; 2007 Mar 29-30; San Antonio, Tx.

9. Garmyn AJ, Hilton GG, Mateescu RG, Morgan JB, Reecy JM, Tait RG Jr., et al. Estimation of relationships between mineral concentration and fatty acid composition of longissimus muscle and beef palatability traits. J Anim Sci. 2011;89:2849-58. https://doi.org/10.2527/jas.20103497

10. Collins CA, Olsen I, Zammit PS, Heslop L, Petrie A, Partridge TA, et al. Stem cell function, self-renewal, and behavioral heterogeneity of cells from the adult muscle satellite cell niche. Cell. 2005;122:289-301. https://doi.org/10.1016/j.cell.2005.05.010

11. Shefer G, Wleklinski-Lee M, Yablonka-Reuveni Z. Skeletal muscle satellite cells can spontaneously enter an alternative mesenchymal pathway. J Cell Sci. 2004;117:5393-404. https://doi. org/10.1242/jcs.01419

12. Csete M, Walikonis J, Slawny N, Wei Y, Korsnes S, Doyle JC, et al. Oxygen-mediated regulation of skeletal muscle satellite cell proliferation and adipogenesis in culture. J Cell Physiol. 2001;189:189-96. https://doi.org/10.1002/jcp.10016

13. Teboul L, Gaillard D, Staccini L, Inadera H, Amri EZ, Grimaldi PA. Thiazolidinediones and fatty acids convert myogenic cells into adipose-like cells. J Biol Chem. 1995;270:28183-7. https://doi.org/10.1074/jbc.270.47.28183

14. Li XZ, Yan Y, Zhang JF, Sun JF, Sun B, Yan CG, et al. Oleic acid in the absence of a PPAR $\gamma$ agonist increases adipogenic gene expression in bovine muscle satellite cells1. J Anim Sci. 2019;97:4114-23. https://doi.org/10.1093/jas/skz269

15. Satory DL, Smith SB. Conjugated linoleic acid inhibits proliferation but stimulates lipid filling of murine 3T3-L1 preadipocytes.J Nutr. 1999;129:92-7. https://doi.org/10.1093/jn/129.1.92

16. Deutsch MJ, Schriever SC, Roscher AA, Ensenauer R. Digital image analysis approach for lipid droplet size quantitation of Oil Red O-stained cultured cells. Anal Biochem. 2014;445:87-9. https://doi.org/10.1016/j.ab.2013.10.001

17. Kook SH, Choi KC, Son YO, Lee KY, Hwang IH, Lee HJ, et al. Satellite cells isolated from adult Hanwoo muscle can proliferate and differentiate into myoblasts and adipose-like cells. Mol Cells. 2006;22:239-45.

18. Xu J, Liu D, Yin H, Tong H, Li S, Yan Y. Fatty acids promote bovine skeletal muscle satellite cell differentiation by regulating ELOVL3 expression. Cell Tissue Res. 2018;373:499-508. https://doi.org/10.1007/s00441-018-2812-3

19. Cassar-Malek I, Langlois N, Picard B, Geay Y. Regulation of bovine satellite cell proliferation and differentiation by insulin and triiodothyronine. Domest Anim Endocrinol. 1999;17:37388. https://doi.org/10.1016/s0739-7240(99)00055-7

20. Seale P, Rudnicki MA. A new look at the origin, function, and "stem-cell" status of muscle sat- 
ellite cells. Dev Biol. 2000;218:115-24. https://doi.org/10.1006/dbio.1999.9565

21. Han RH, Wang M, Fang X, Han X. Simulation of triacylglycerol ion profiles: bioinformatics for interpretation of triacylglycerol biosynthesis. J Lipid Res. 2013;54:1023-32. https://doi. org/10.1194/jlr.M033837

22. Choi SH, Chung KY, Johnson BJ, Go GW, Kim KH, Choi CW, et al. Co-culture of bovine muscle satellite cells with preadipocytes increases $\operatorname{PPAR} \gamma$ and $\mathrm{C} / \mathrm{EBP} \beta$ gene expression in differentiated myoblasts and increases GPR43 gene expression in adipocytes. J Nutr Biochem. 2013;24:539-43. https://doi.org/10.1016/j.jnutbio.2012.01.015

23. Choi SH, Park SK, Johnson BJ, Chung KY, Choi CW, Kim KH, et al. AMPK $\alpha, \mathrm{C} / \mathrm{EBP} \beta$, $\mathrm{CPT} 1 \beta$, GPR43, PPAR $\gamma$, and SCD gene expression in single- and co-cultured bovine satellite cells and intramuscular preadipocytes treated with palmitic, stearic, oleic, and linoleic acid. Asian-australas J Anim Sci. 2015;28:411-9. https://doi.org/10.5713/ajas.14.0598

24. Tontonoz P, Hu E, Spiegelman BM. Regulation of adipocyte gene expression and differentiation by peroxisome proliferator activated receptor $\gamma$. Curr Opin Genet Dev. 1995;5:571-6. https://doi.org/10.1016/0959-437x(95)80025-5

25. Hollenberg AN, Susulic VS, Madura JP, Zhang B, Moller DE, Tontonoz P, et al. Functional antagonism between CCAAT/Enhancer binding protein- $\alpha$ and peroxisome proliferator-activated receptor-gamma on the leptin promoter. J Biol Chem. 1997;272:5283-90. https://doi. org/10.1074/jbc.272.8.5283

26. Kadegowda AKG, Burns TA, Pratt SL, Duckett SK. Inhibition of stearoyl-CoA desaturase 1 reduces lipogenesis in primary bovine adipocytes. Lipids. 2013;48:967-76. https://doi. org/10.1007/s11745-013-3823-1

27. Kim E, Lee JH, Ntambi JM, Hyun CK. Inhibition of stearoyl-CoA desaturase1 activates AMPK and exhibits beneficial lipid metabolic effects in vitro. Eur J Pharmacol. 2011;672:3844. https://doi.org/10.1016/j.jphar.2011.09.172

28. Hardie DG, Carling D. The AMP-activated protein kinase--fuel gauge of the mammalian cell? Eur J Biochem. 1997;246:259-73. https://doi.org/10.1111/j.1432-1033.1997.00259.x

29. Bijland S, Mancini SJ, Salt IP. Role of AMP-activated protein kinase in adipose tissue metabolism and inflammation. Clin Sci. 2013;124:491-507. https://doi.org/10.1042/cs20120536

30. Fernández-Veledo S, Vázquez-Carballo A, Vila-Bedmar R, Ceperuelo-Mallafré V, Vendrell $\mathrm{J}$. Role of energy- and nutrient-sensing kinases AMP-activated protein kinase (AMPK) and mammalian target of rapamycin (mTOR) in adipocyte differentiation. IUBMB Life. 2013;65:572-83. https://doi.org/10.1002/iub.1170

31. Zong H, Ren JM, Young LH, Pypaert M, Mu J, Birnbaum MJ, et al. AMP kinase is required for mitochondrial biogenesis in skeletal muscle in response to chronic energy deprivation. Proc Nati Acad Sci USA. 2002;99:15983-7. https://doi.org/10.1073/pnas.252625599

32. Bonen A, Parolin ML, Steinberg GR, Calles-Escandon J, Tandon NN, Glatz JF, et al. Triacylglycerol accumulation in human obesity and type 2 diabetes is associated with increased rates of skeletal muscle fatty acid transport and increased sarcolemmal FAT/CD36. FASEB J. 2004;18:1144-6. https://doi.org/10.1096/fj.03-1065fje

33. Kelley DE, Goodpaster B, Wing RR, Simoneau JA. Skeletal muscle fatty acid metabolism in association with insulin resistance, obesity, and weight loss. Am J Physiol. 1999;277:E1130-41. https://doi.org/10.1152/ajpendo.1999.277.6.E1130

34. Kelley DE, Reilly JP, Veneman T, Mandarino LJ. Effects of insulin on skeletal muscle glucose storage, oxidation, and glycolysis in humans. Am J Physiol. 1990;258:E923-9. https://doi. org/10.1152/ajpendo.1990.258.6.E923

35. Simoneau JA, Veerkamp JH, Turcotte LP, Kelley DE. Markers of capacity to utilize fatty acids 
in human skeletal muscle: relation to insulin resistance and obesity and effects of weight loss. FASEB J.1999;13:2051-60. https://doi.org/10.1096/fasebj.13.14.2051

36. Chung KY, Johnson BJ. Melengestrol acetate enhances adipogenic gene expression in cultured muscle-derived cells.J Anim Sci. 2009;87:3897-904. https://doi.org/10.2527/jas.2008-1645

37. Thiam AR, Farese RV, Jr., Walther TC. The biophysics and cell biology of lipid droplets. Nat Rev Mol Cell Biology. 2013;14:775-86. https://doi.org/10.1038/nrm3699

38. Bickel PE, Tansey JT, Welte MA. PAT proteins, an ancient family of lipid droplet proteins that regulate cellular lipid stores. Biochim Biophys Acta. 2009;1791:419-40. https://doi. org/10.1016/j.bbalip.2009.04.002

39. Greenberg AS, Egan JJ, Wek SA, Garty NB, Blanchette-Mackie EJ, Londos C. Perilipin, a major hormonally regulated adipocyte-specific phosphoprotein associated with the periphery of lipid storage droplets. J Biol Chem. 1991;266:11341-6. https://doi.org/10.1016/S00219258(18)99168-4

40. Wolins NE, Brasaemle DL, Bickel PE. A proposed model of fat packaging by exchangeable lipid droplet proteins. FEBS Lett. 2006;580:5484-91. https://doi.org/10.1016/j.febslet.2006.08.040

41. Heid HW, Moll R, Schwetlick I, Rackwitz HR, Keenan TW. Adipophilin is a specific marker of lipid accumulation in diverse cell types and diseases. Cell Tiss Res. 1998;294:309-21. https:// doi.org/10.1007/s004410051181

42. Brasaemle DL, Barber T, Wolins NE, Serrero G, Blanchette-Mackie EJ, Londos C. Adipose differentiation-related protein is an ubiquitously expressed lipid storage droplet-associated protein.J Lipid Res. 1997;38:2249-63. https://doi.org/10.1016/S0022-2275(20)34939-7

43. Imamura M, Inoguchi T, Ikuyama S, Taniguchi S, Kobayashi K, Nakashima N, et al. ADRP stimulates lipid accumulation and lipid droplet formation in murine fibroblasts. Am J Physiol Endocrinol Metab. 2002;283:E775-83. https://doi.org/10.1152/ajpendo.00040.2002

44. Havel PJ. Update on adipocyte hormones: regulation of energy balance and carbohydrate/lipid metabolism. Diabetes. 2004;53 Suppl :S143-51. https://doi.org/10.2337/diabetes.53.2007.s143

45. Trayhurn P. Endocrine and signalling role of adipose tissue: new perspectives on fat. Acta Physiol Scand. 2005;184:285-93. https://doi.org/10.1111/j.1365-201X.2005.01468.x

46. Berg AH, Combs TP, Du X, Brownlee M, Scherer PE. The adipocyte-secreted protein Acrp30 enhances hepatic insulin action. Nat Med. 2001;7:947-53. https://doi.org/10.1038/90992

47. Ouchi N, Kihara S, Arita Y, Maeda K, Kuriyama H, Okamoto Y, et al. Novel modulator for endothelial adhesion molecules: adipocyte-derived plasma protein adiponectin. Circulation. 1999;100:2473-6. https://doi.org/10.1161/01.cir.100.25.2473

48. Yamauchi T, Kamon J, Waki H, Terauchi Y, Kubota N, Hara K, et al. The fat-derived hormone adiponectin reverses insulin resistance associated with both lipoatrophy and obesity. Nat Med. 2001;7:941-6. https://doi.org/10.1038/90984

49. Christiaens V, Van Hul M, Lijnen HR, Scroyen I. CD36 promotes adipocyte differentiation and adipogenesis. Biochim Biophys Acta. 2012;1820:949-56. https://doi.org/10.1016/ j.bbagen.2012.04.001

50. Luiken JJ, Chanda D, Nabben M, Neumann D, Glatz JF. Post-translational modifications of CD36 (SR-B2): implications for regulation of myocellular fatty acid uptake. Biochim Biophys Acta. 2016;1862:2253-8. https://doi.org/10.1016/j.bbadis.2016.09.004 